\title{
A new fossil genus of the tribe Synchitini Erichson (Tenebrionoidea: Zopheridae: Colydiinae) from Eocene Baltic amber
}

\author{
VITALII I. ALEKSEEV ${ }^{1,2} \&$ MAXIMILIAN G. PANKOWSKI ${ }^{3, *}$ \\ ${ }^{I}$ Shirshov Institute of Oceanology, Russian Academy of Sciences, Nahimovskiy prospekt 36, Moscow 117997, Russia \\ ${ }^{2}$ Kaliningrad Regional Amber Museum, Marshal Vasilevskii square 1, Kaliningrad 236016, Russia \\ ${ }^{3} 16405$ Fox Valley Terrace, Rockville, Maryland 20853, USA \\ "=alekseew0802@yahoo.com; @ https://orcid.org/0000-0003-4390-5443

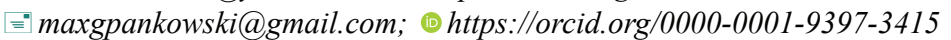 \\ *Corresponding author: ఏ"maxgpankowski@gmail.com
}

\begin{abstract}
A new extinct monotypic genus and species of the cylindrical bark beetles, Semicoxelus sontagae gen. et sp. nov., is described and figured based on an inclusion in Baltic amber. The new representative from the Eocene is classified within the synchitine tribe and placed near the morphologically close extant genera, including Coxelus Dejean, Diodesma Latreille and Notocoxelus Ślipiński \& Lawrence. The description and comparison of the new fossil are accompanied by a brief discussion focusing on an interesting morphological character of cylindrical bark beetles: the presence/absence of interfacetal setae on the eyes.
\end{abstract}

Keywords: Cenozoic, Paleogene, succinite, new taxa, cylindrical bark beetle, interfacetal setation

\section{Introduction}

About 10 different genera of the cylindrical bark beetles have been reported from Baltic amber (Klebs, 1910; Spahr, 1981). Several of them are confirmed by subsequent descriptions, but other generic reports are "in limbo" and have neither been confirmed nor refuted by researchers during the last 100 years. The study of such "still reported" taxa remains important, however, for making conclusions about different questions connected with Baltic amber biota. The resulting findings of representatives from still living genera in amber could be especially useful for palaeoclimatologic, palaeoecologic and zoogeographic implications (Bogri et al., 2020; Bukejs \& Legalov, 2019; Shavrin \& Yamamoto, 2019; Szawaryn \& Tomaszewska, 2020, etc.), whereas the study of findings of the palaeoendemic taxa, assignable to extinct genera or even taxa of higher levels, is more important for the study of the evolution of appropriate groups of beetles and research of the evolutionary trends of certain morphological characters within the groups (e.g., Alekseev \& Alekseev, 2019; Kundrata et al., 2020; Schmidt et al., 2019; Tshernyshev, 2020 etc.).

Representatives of the genera Coxelus Dejean and Diodesma Latreille from Baltic amber were first reported by Klebs (1910). Only a few years ago, the first Eocene species assigned to the present-day Diodesma was described (Alekseev \& Bukejs, 2016). In this paper, we document a new fossil beetle resembling Coxelus from Eocene Baltic amber found in the Kaliningrad Region in Russia. The new separate monotypic genus is proposed for this fossil, despite the morphological similarity and possible taxonomic affinity to several living synchitine genera, especially to Coxelus.

\section{Material and methods}

The amber piece MAIG 6693 containing the holotype is deposited in the Museum of Amber Inclusions (Muzeum Inkluzji w Bursztynie), Department of Invertebrate Zoology and Parasitology, Faculty of Biology, University of Gdańsk, Poland.

Preparation of the amber specimen for examination and photography was performed by Marius Veta (Palanga, Lithuania). The amber piece was cut and polished to allow a better view of the inclusion. Photographs (Figs 1A, B, 2A, B) were taken using a Canon DSLR camera with a macro lens. Extended depth of field at high magnifications was achieved by combining multiple images from a range of focal planes using a focus stacking software Helicon Focus.

The observations and measurements were made using stereoscopic microscope Olympus SZX 16 and MBS- 
9. The reconstruction (Fig. 2C) was made by free-hand drawing during the examination of the original specimen. All images were edited using Adobe Photoshop ${ }^{\circledR} 7.0$ software.

The following sources were used for the generic attribution and comparison with extant and extinct taxa as well as for the morphological terminology used in this paper: Reitter (1882); Poggi (1985); Ślipiński (1985); Stephan (1989); Schuh (1998, 1999); Machado (2012); Ivie et al. (2016); Alekseev \& Bukejs 2016; Deng et al. (2017); Háva (2019); Bullis (2020); and Cheng et al. (2020).

There are two main points of view on the systematic level of the cylindrical bark beetles lineage at the moment: the group is treated as the separate family Colydiidae (e.g., Beutel \& Friedrich, 2005; Zaitsev \& Kompantsev, 2018) or as the subfamily Colydiinae within the compound family Zopheridae (e.g., Ślipiński \& Lawrence, 1999; Ślipiński \& Schuh, 2008; Lord \& Ivie, 2016). We follow the second variant, while noting that the question of family/subfamily is still a matter of debate and beyond the scope of this paper.

\section{Systematic palaeontology}

\section{Family Zopheridae Solier, 1834 \\ Subfamily Colydiinae Erichson, 1842 \\ Tribe Synchitini Erichson, 1845 \\ Genus Semicoxelus gen. nov.}

Type species. Semicoxelus sontagae sp. nov., here designated.

Etymology. The new genus-group name Semicoxelus is composed of the Latin prefix "semi-" (meaning "half" with the sense "partially", "incompletely", "somewhat") and the genus name "Coxelus". The gender is masculine.

Diagnosis. Semicoxelus gen. nov. can be classified into the diverse tribe Synchitini within the subfamily Colydiinae based on the following characteristics: (1) dorsally concealed antennal insertions; (2) antennae glabrous, lacking scale-like setae, 11-segmented with 2segmented club; (3) procoxal cavities open behind; (4) all tarsi tetramerous, not dilated; (5) apex of protibiae without spurs; and (6) metacoxae narrowly separated.

Remarks. Semicoxelus gen. nov. morphologically resembles several extant genera (or several representatives of these genera) of the tribe Synchitini such as Tarphius Erichson, 1845; Franzorphius Schuh, 1998; Namunaria Reitter, 1882; Coxelus Dejean, 1821; Diodesma Latreille, 1829; and Notocoxelus Ślipiński \& Lawrence, 1997. In spite of the apparent similarity, we conclude that the studied fossil cannot be attributed to any of these genera and thus we propose a new genus for this beetle. The new genus clearly differs from Tarphius in absence of antennal cavities on the prothoracic hypomera; from Franzorphius in the elytra and pronotum without any gibbosities; from Namunaria in lacking lateral expansions on the prosternal process and in abdominal ventrite 5 without a deep preapical groove; from Palearctic representatives of Coxelus in the absence of interfacetal setae, in the absence of additional setal patches on the elytra, and in thicker antennae; from the European native Diodesma in the antennal insertions situated close to the eyes, in the non-widened head area under antennal insertions, and in the partially explanate pronotal sides; from the Southern Hemisphere inhabitant Notocoxelus in the absence of interfacetal setation, in the absence of a groove on the last abdominal ventrite, in open procoxal cavities, and in the absence of a canthus on the posterior margin of the eyes. Semicoxelus gen. nov. differs from other similar synchitines in a distinctly long metaventrite (longer than the first ventrite) and in the narrowly separated by triangular abdominal process metacoxae.

Semicoxelus sontagae gen. et sp. nov., can be easily distinguished from the previously described six species from Baltic amber of the tribe (four genera: Diodesma; Xylolaemus Reitter; Endophloeus Dejean, 1834; and Bitoma Herbst, 1793). The new species may be confused only with the apparently similar (dorsally convex elytra, pronotum with tubercles) Diodesma slipinskii Alekseev \& Bukejs, 2016. The Baltic amber species Diodesma slipinskii (body length of the holotype is $2.25 \mathrm{~mm}$ ) differs from the new genus in the head structure (antennal insertions clearly distant from eyes; eyes prominent and conical; head widest between antennal insertions; antennae stouter); rounded process of abdominal ventrite 1 and comparatively long ventrite 1 and short metaventrite. The single known Mesozoic synchitine genus Paleoendeitoma Deng, Ślipiński, Ren \& Pang, 2017 from Burmese amber clearly differs from the newly described taxon by a loose antennal club, elytra with 10 regular rows of punctures, etc.

\section{Semicoxelus sontagae sp. nov.}

(Figs 1, 2)

Material. Holotype: No. 6693 [MAIG], adult, sex unknown. Complete beetle inclusion included in flat, transparent, yellow piece of amber with dimensions $24 \times 12 \times 5 \mathrm{~mm}$ (weight about $1.0 \mathrm{~g}$ ) without any further fixation. The complete beetle is well preserved, but not perfectly visible in all positions due to cracks in the amber. Organic syninclusions are represented by the stellate fagacean trichomes, small detrital particles, several insect pellets and four fragments (9-15 segments) of antennae or caudal filaments of perhaps Zygentoma or Archaeognatha. 

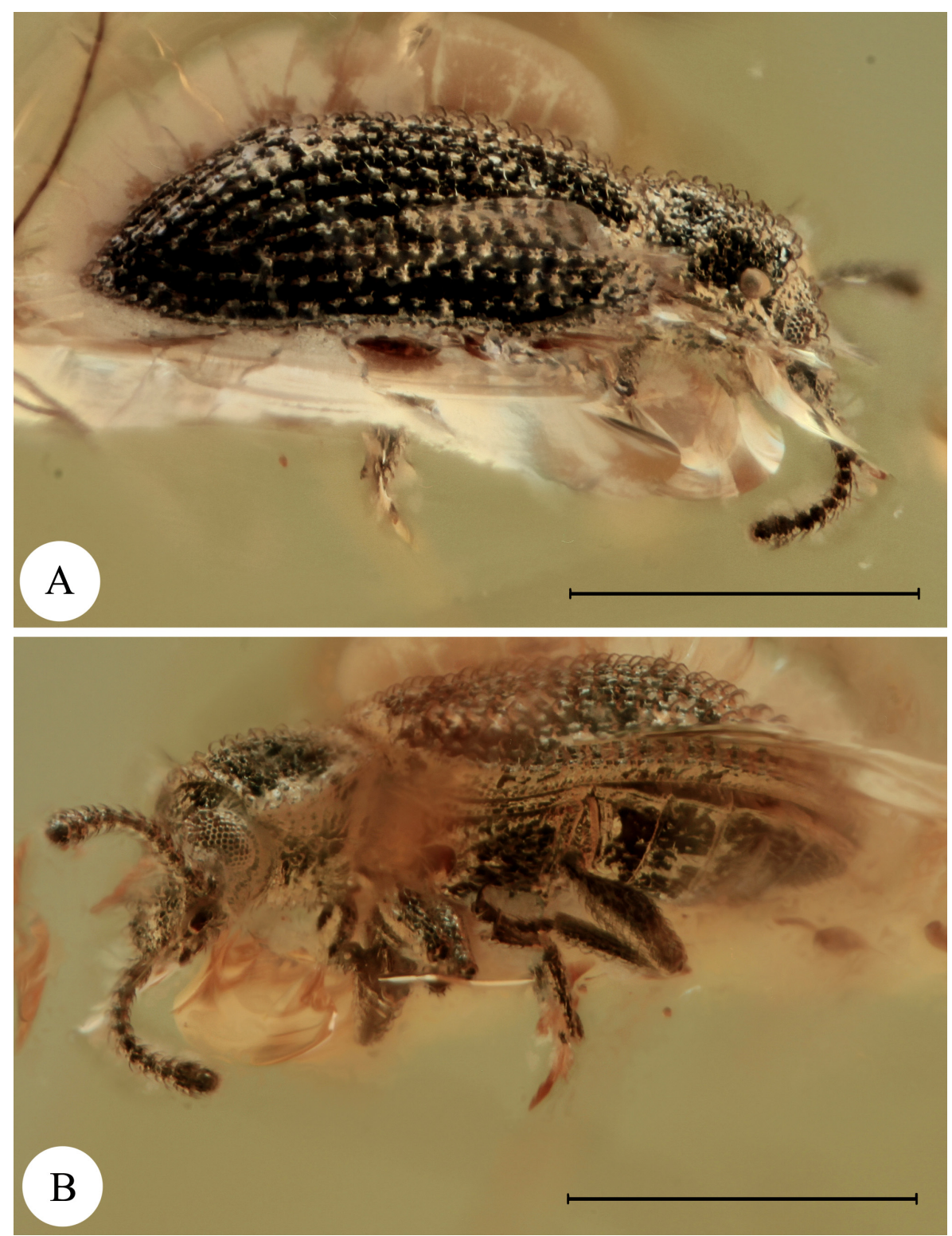

FIGURE 1. Semicoxelus sontagae gen. et sp. nov., holotype, No. MAIG 6693, habitus. A, Right lateral view. B, Left ventro-lateral view. Scale bars $=1.0 \mathrm{~mm}$.

Etymology. The specific name honors Dr. Elżbieta Sontag, the curator of the Museum of Amber Inclusions (University of Gdańsk, Gdańsk, Poland), for her deep dedication to the preservation and study of scientifically important amber specimens.

Diagnosis. As stated above, for the new genus.

Type locality and horizon. "Primorskoe" mine, Yantarny settlement (formerly Palmnicken), Sambian (Samland) Peninsula, Kaliningrad Region, Russia. Baltic amber from Eocene amber-bearing Blaue Erde deposits.

Description. Body elongate, convex dorsally (Fig. 1A); dark, unicolorous; dorsum with apparent tubercles and curved bristles.

Head. Head capsule (Figs 1B, 2A, C) prognathous, transverse. Anterior margin of clypeus rounded. Clypeus and frons slightly convex; fronto-clypeal suture in the form of a weak transverse impression. Sculpture of frons consisting of small rounded tubercles. Each tubercle with a puncture bearing a short, slightly curved bristle. Tubercles small, about as wide in diameter as an eye facet. Eyes coarsely faceted, vertical, weakly convex, slightly emarginated near antennal insertions. Interfacetal setae absent. Antennal insertions (Fig. 2A) close to anterior margin of eye. Antennae short, extending to base of pronotum, 11-segmented with a distinct, 2segmented club. Antennal setation sparse, dark, semierect. Subantennal grooves absent. Scape almost not visible in dorsal aspect, concealed by expansion of the frons. Scape and pedicel cylindrical; antennomeres 3-4 subquadrate; antennomeres 5-6 transverse; antennomeres 7-9 slightly rounded and almost equal in width and length; antennomere 10 the widest, distinctly transverse; 

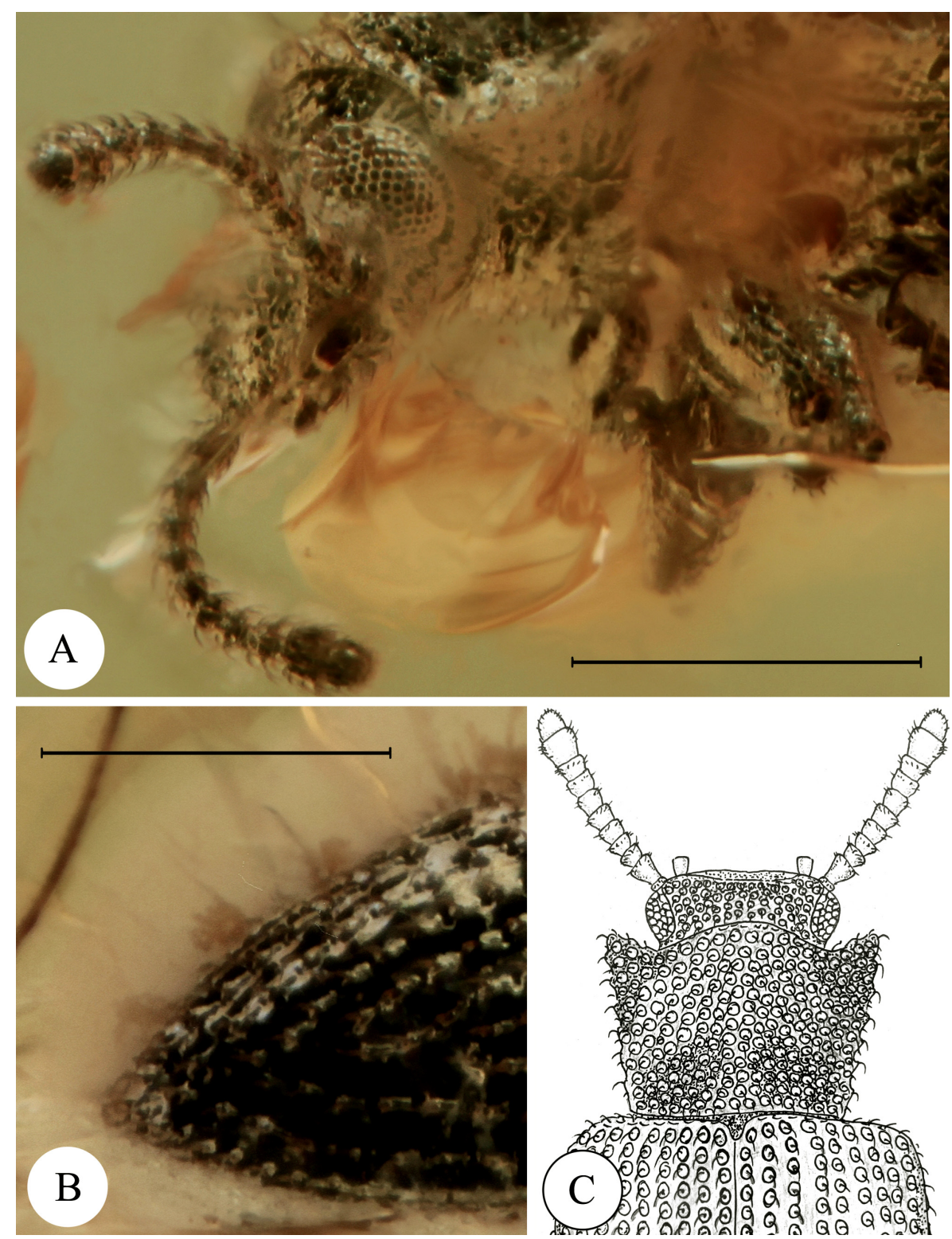

FIGURE 2. Semicoxelus sontagae gen. et sp. nov., holotype, No. MAIG 6693. A, Head, antennae, and prothorax in ventro-lateral view, scale bar $=0.5 \mathrm{~mm}$. B, Elytral apex with rows of tubercles, lateral view, scale bar $=0.5 \mathrm{~mm}$. C, Forebody, dorsal view, reconstruction.

antennomere 11 elongate, egg-shaped. Labial palpi present. Last maxillary palpomere truncate.

Thorax. Pronotum transverse, widest at anterior angles. Anterior angles prominent, rounded; posterior angles right-angled; lateral margins of pronotum weakly divergent and explanate anteriorly, finely denticulate (bearing seven small denticles). Pronotal disc convex, non-carinate, without median depression, with two shallow oblique subbasal impressions. Hypomera without excavations; procoxae separated by apically rounded, quite wide (narrower than coxal diameter), parallel-sided prosternal process. Procoxal cavities open. Sculpture of prothorax consists of tubercles: tubercles of pronotum large, rounded, 4 times larger than tubercles on head, separated by distance approximately $0.3-0.5$ times tubercle diameter; prosternal tubercles lesser, about 2 times larger than tubercles on head. Each tubercle bears curved recumbent seta.

Meso- and metaventrites sculptured like prosternum. Mesocoxal cavities closed. Meso- and metacoxae narrowly separated. Metaventrite longer than abdominal ventrite 1. The ratio of lengths pro- to meso- to metaventrite to abdomen is approximately: $5-4-6-18$.

Scutellum poorly visible on the specimen, possibly small and triangular. Elytra (Figs 1A, 2C) almost parallelsided, non-carinate, convex, without dorsal gibbosities, distinctly wider than pronotum basally. Elytral lateral margins crenulate, weakly explanate behind the humeri. Elytral apices jointly rounded. Elytral surface with elytral striae composed of a series of elongate tubercles, smaller 
toward apices and bearing of curved, recumbent, directed apically setae. Each elytron with 9 rows of setiferous tubercles, row 1 ending separately at apex of elytra; row 2 connected at apex with row 9 , row 3 with row 8 . The length of rows 4 and 5 consists 0.8 of elytral length; the rows 6 and 7 the shortest, about 0.7 of elytral length (Fig. 2B). Interstriae without setation. The scutellar striole not apparent. Epipleura distinct, reaching abdominal ventrite 3. Hind wings are not apparent.

Legs. Femora stout and broad. Tibiae straight, not expanded apically, sparsely covered by recumbent pubescence. All tarsi 4-segmented; tarsomere 4 the longest. Metatarsomere 4 as long as metatarsomeres 1-3 combined. Tarsal claws long, simple, curved, longer than tarsomere 3.

Abdomen. With five similarly articulated ventrites. Ventrite length ratios: 15-10-10-9-12. Ventrite 5 rounded, simple, without groove. Intercoxal process of abdominal ventrite 1 narrowly triangular, acute. Abdominal punctation with sparse setiferous punctures, distance between points 2.0-3.0 times diameter of each puncture.

Measurements. Body length approximately $1.85 \mathrm{~mm}$ (measured dorsally, head obliquely directed as preserved), elytral length $1.43 \mathrm{~mm}$; pronotal length $0.36 \mathrm{~mm}$; head length (measured laterally) $0.28 \mathrm{~mm}$. Maximum body width $1.14 \mathrm{~mm}$ (elytra medially); humeral width 0.86 $\mathrm{mm}$; pronotal width $0.6 \mathrm{~mm}$.

Remarks. The reduction of metathoracic wings is connected to the shortening of the metasventrite; and vice versa, the developed metathoracic wings are connected with comparatively long and developed metaventrite, as is seen in the extant synchitine genus Namunaria (Schuh, 1999). We cannot observe the metathoracic wings of the fossil because they are hidden under the elytra, but we can suppose their functionality based on the beetle's distinctly long metaventrite.

\section{Discussion}

The described fossil can be distinguished from modern European representatives of Coxelus Dej. and genus Notocoxelus Ślipiński \& Lawrence, inter alia, by the absence of interfacetal setae on the eyes. Here we reflect on this character and its role in the beetle's biology and its systematics.

Interfacetal setation (or pubescence), hereafter abbreviated as IFS, situated between the ommatidia on the compound eyes of adults, is a relatively common character of the representatives of the Tenebrionoidea lineage. It can be observed in such families as Anthicidae, Melandryidae, Mordellidae, Mycteridae, Tetratomidae and Zopheridae (e.g., Nikitsky \& Pollock, 2010; Pollock, 2016). The character is not limited to the Tenebrionoidea and can be seen in several representatives of other unrelated beetles groups (Coccinellidae, Dryopidae, Eucinetidae, Lutrochidae, Vesperidae, etc.). The form and length of IFS can vary, and the setae can be hair-like, bristle-like or scale-like. The base of each movable seta is flexible and connected with the integument by the membrane. Sometimes IFS can be very short and inconspicuous. IFS is an inheritable genetically determined trait and has specific characteristics; however, several setae can sometimes be lost during the lifespan of the adult specimen. In present-day zopherid beetles, the presence of IFS on eyes is sometimes considered a character that can help distinguish one genus from another (Lord \& Ivie, 2016). The presence or absence of IFS is mentioned in the generic diagnosis for some species (for example, Schuh, 1999 or Ślipiński \& Lawrence, 1999); however, this character was not used in the comprehensive phylogenetic analyses of Ślipiński \& Lawrence (1999).

The adaptive role of IFS in beetles is unclear. We assume IFS could hypothetically be: (a) protective against small particles blocking the vision (functioning as "eyelashes"); (b) receptive during the sustained movements in substrate (acting as "whiskers"); or (c) non-adaptive, and neutral for beetle survival. We suppose the presence of IFS would not improve a beetle's ability to see (it could make the visual orientation even worse) and could be neutral or helpful for survival only in the case of a secretive mode of life in the dark or spatially restricted microhabitats (e.g., in wood of rotting trunks, on the ground, among leaf litter or under the bark of a tree). Consequently, the character state "presence of IFS" is indicative of beetles that are more cryptic (e.g., subcortical), or active at twilight or at night. The absence of IFS can be treated as a plesiomorphic character state, and the "presence of IFS" as a secondary, specialized and perhaps independently seen in different groups, trait.

The wing reduction, adjoined (by analogy with living Namunaria species, see Schuh, 1999) with short metaventrite, i.e., shorter than ventrite 1 , should be closely associated with a persistent habitat and the absence of active distant dispersal. In contrast, the long metaventrite, i.e., longer than ventrite 1, could indicate the presence of developed wings and flying capability (as is possible in the newly described species). Considering only two abovementioned characters (IFS and length of metaventrite), the newly described beetle has primary character states ("absent" and "long") and the present-day Coxelus representatives can be considered derivative and specialized (having the setae "present" and metaventrite "short"). In this respect, Eocene Fennosarmatian Semicoxelus sontagae gen. et sp. nov. could presumably be a distant ancestor of the modern western Palearctic Coxelus representatives. 
All of the abovementioned is worth taking into consideration when examining the relationships within the family and the tribe. When the tribe is analysed in the future, researchers should study the close relationships between the nine known species of modern Coxelus representatives inhabiting North America [2 spp.: $C$. serratus Horn, 1885 and C. longus (Stephan, 1989)], western Palearctic [5 spp.: C. alinae Dajoz, 1973; C. bituberculatus (Frivaldszky, 1894); C. humeridens Reitter, 1885; C. luteopilosus Pic, 1901; C. pictus (Sturm, 1807)]; eastern Palearctic [1 sp. from Nepal: C. yeti Ślipiński, 1985] and Afrotropical [1 sp. from Mauritius: C. insularis (Grouvelle, 1899)] and their resemblance to this genus known from a single specimen of Semicoxelus gen. nov. of Eocene European amber. The question of the role of IFS in beetle biology is an intriguing one. It can only be answered by carefully analysing a variety of comparative relatives and their behaviour.

\section{Acknowledgements}

We sincerely thank Madeline and Mark Pankowski (Rockville, Maryland, USA) for donating this specimen to the Museum of Amber Inclusions, Dr. Elżbieta Sontag (MAIG, Gdańsk, Poland) for the loan of the material for our study and Marius Veta (Palanga, Lithuania) for granting us permission to use his photographs in the paper. We express our gratitude to the anonymous reviewers and the editor for their valuable suggestions that improved our manuscript. The study of V.I.A. was done with the support of the state assignment of IO RAS (Theme No.01492019-0013).

\section{References}

Alekseev, V.I. \& Alekseev, P.I. (2019) New fossil cylindrical bark beetle (Zopheridae: Colydiinae: Gempylodini) from Eocene Baltic amber: an abnormal or intermediate form within Tenebrionoidea. Palaeontologia Electronica, 22.2.43A, 110.

https://doi.org/10.26879/963

Alekseev, V.I. \& Bukejs, A. (2016) New Zopheridae (Coleoptera: Tenebrionoidea) from Baltic amber. Zootaxa, 4178 (3), 409 427.

https://doi.org/10.11646/zootaxa.4178.3.6

Beutel, R.G. \& Friedrich, F. (2005) Comparative study of larvae of Tenebrionoidea (Coleoptera: Cucujiformia). European Journal of Entomology, 102, 241-264. https://doi.org/10.14411/eje.2005.037

Bogri, A., Solodovnikov A., Kypke, J.L. \& Żyła, D. (2020) Baltic amber members of the extant Micrillus-Scymbalium lineage of the Paederinae rove beetles (Coleoptera, Staphylinidae) and their systematic and ecological significance. Invertebrate Systematics, 34, 451-473.

https://doi.org/10.1071/IS19070

Bukejs, A. \& Legalov, A.A. (2019) A new species of the genus Dorytomus Germar, 1817 (Coleoptera: Curculionidae) from Baltic amber. Entomologica Fennica, 30, 173-178. https://doi.org/10.33338/ef.87174

Bullis, D.A. (2020) A new species of Paleoendeitoma (Coleoptera: Zopheridae: Colydiinae) from mid-Cretaceous Burmese amber. Palaeoentomology, 3 (1), 46-49.

https://doi.org/10.11646/palaeoentomology.3.1.6

Cheng, G.M., Tihelka, E., Shi, H., Tian, L., Huang, D.Y. \& Cai, C.Y. (2020) Specialised subcortical cylindrical bark beetles from mid-Cretaceous Burmese amber (Coleoptera: Zopheridae: Colydiinae). Historical Biology, 1-7. https://doi.org/10.1080/08912963.2020.1819261

Deng, C., Ślipiński, S.A., Ren, D. \& Pang, H. (2017) The first Mesozoic colydiid (Coleoptera: Zopheridae: Colydiinae) from the Upper Cretaceous amber of Myanmar. Cretaceous Research, 78, 71-77. https://doi.org/10.1016/j.cretres.2017.04.010

Háva, J. (2019) A new species of Paleoendeitoma Deng, Ślipiński, Ren \& Pang, 2017 (Coleoptera: Zopheridae: Colydiinae) from Upper Cretaceous Burmese amber. Folia Heyrovskyana, Series A, 27 (2), 9-12.

Ivie, M.A., Lord, N.P., Foley, I.A. \& Ślipiński, S.A. (2016) Colydiids of the New World: a key and nomenclatural acts 30 years in the making (Coleoptera: Zopheridae: Colydiinae). The Coleopterists Bulletin, 70 (4), 755-788. https://doi.org/10.1649/0010-065X-70.4.755

Klebs, R. (1910) Über Bernsteineinschlüsse im Allgemeinen und die Coleopteren meiner Bernsteinsammlung. Schriften der Physikalisch-ökonomischen Gesellschaft zu Königsberg, 51 (3), 217-242.

Kundrata, R., Packova, G. \& Hoffmannova, J. (2020) Fossil genera in Elateridae (Insecta, Coleoptera): a Triassic origin and Jurassic diversification. Insects, 11, 394. https://doi.org/10.3390/insects 11060394

Lord, N.P. \& Ivie, M.A. (2016) Several new genera and species of new world Synchitini (Coleoptera: Zopheridae: Colydiinae). The Coleopterists Bulletin, 70 (4), 715-753. https://doi.org/10.1649/0010-065X-70.4.715

Machado, A. (2012) Two new Tarphius species from Macaronesia (Coleoptera, Zopheridae). Journal of Natural History, 46 (9-10), 637-643. https://doi.org/10.1080/00222933.2012.654477

Nikitsky, N.B. \& Pollock, D.A. (2010) Melandryidae. In: Leschen, R.A.B., Beutel, R.G. \& Lawrence, J.F. (Eds), Handbook of Zoology. Vol. 2. Coleoptera, Beetles. Morphology and Systematics (Elateroidea, Bostrichiformia, Cucujiformia partim). Walter de Gruyter GmbH \& Co, Berlin, pp. 520533.

Poggi, R. (1985) Caratteri diagnostici e distribuzione delle specie 
italiane del genere Diodesma Latreille (Col. Colydiidae). Annali del Museo civico di storia naturale Giacomo Doria, Genova, 85, 363-374.

Pollock, D.A. (2016) Revision of the genus Thisiomorphus Pic (Coleoptera: Mycteridae: Eurypinae) with descriptions of eleven new species from Central and South America and a key to genera of Neotropical Eurypinae. Zootaxa, 4093 (3), 301-322.

https://doi.org/10.11646/zootaxa.4093.3.1

Reitter, E. (1882) Bestimmungs-Tabellen der europäischen Coleopteren. VI. Enhaltend die Familien: Colydiidae, Rhysodidae, Trogositidae. Verhandlungen des Naturforschenden Vereines in Brünn, 22 [1881], 113-149.

Shavrin, A.V. \& Yamamoto, S. (2019) Unexpected palaeodiversity of omaliine rove beetles in Eocene Baltic amber (Coleoptera, Staphylinidae, Omaliinae). ZooKeys, 863, 35-83. https://doi.org/10.3897/zookeys.863.34662

Schmidt, J., Scholz, S. \& Kavanaugh, D.H. (2019) Unexpected findings in the Eocene Baltic amber forests: ground beetle fossils of the tribe Nebriini (Coleoptera: Carabidae). Zootaxa, 4701 (4), 350-370. https://doi.org/10.11646/zootaxa.4701.4.2

Schuh, R. (1998) Franzorphius franti gen. et sp. n. from China (Coleoptera: Zopheridae: Colydiinae). Koleopterologische Rundschau, 68, 227-232.

Schuh, R. (1999) Revision of the Oriental species of the genus $\mathrm{Na}$ munaria Reitter, 1882 (Coleoptera: Zopheridae, Colydiinae). Koleopterologische Rundschau, 69, 137-152.

Ślipiński, S.A. (1985) New and little known species of Colydiidae from Asia, Madagascar and Comoro Islands. Annales Zoologici, 39 (10), 181-195.
Ślipiński, S.A. \& Lawrence, J.F. (1999) Phylogeny and classification of Zopheridae sensu novo (Coleoptera: Tenebrionoidea) with a review of the genera of Zopheridae (excluding Monommatini). Annales Zoologici (Warszawa), 49 (1), 1-53.

Ślipiński, S.A. \& Schuh, R. (2008) Zopheridae. In: Löbl, I. \& Smetana, A. (Eds), Catalogue of Palaearctic Coleoptera. Vol. 5. Apollo Books, Stenstrup, pp. 78-87.

Spahr, U. (1981) Systematischer Katalog der Bernstein und Kopalkäfer(Coleoptera). Stuttgarter Beiträge zur Naturkunde, Serie B (Geologie und Paläontologie), 80, 1-107.

Stephan, K.H. (1989) The Bothrideridae and Colydiidae of America north of Mexico (Coleoptera: Clavicornia and Heteromera. Occasional Papers of the Florida State Collection of Arthropods. Vol. 6. Florida Department of Agriculture and Consumer Services, Gainesville, xii +65 pp.

Szawaryn, K. \& Tomaszewska, W. (2020) New and known extinct species of Rhyzobius Stephens, 1829 shed light on the phylogeny and biogeography of the genus and the tribe Coccidulini (Coleoptera: Coccinellidae). Journal of Systematic Palaeontology, 18 (17), 1445-1461. http://dx.doi.org/10.1080/14772019.2020.1769751

Tshernyshev, S.E. (2020) New taxa of soft-winged flower beetles (Coleoptera, Malachiidae) in Baltic amber. Paleontological Journal, 54 (3), 67-75. https://doi.org/10.1134/S0031030120030065

Zaitsev, A.A. \& Kompantsev, A.V. (2018) Description of the larva of Monomma resinorum Hope 1842 (Coleoptera, Zopheridae), with remarks on the composition of the family. Zoologicheski Zhurnal, 97 (11), 1374-1393.

https://doi.org/10.1134/S0044513418110089 